\title{
Reliability and validity of the Dutch version of the maternal antenatal attachment scale
}

\author{
Johan C. H. van Bussel • Bernard Spitz • \\ Koen Demyttenaere
}

Received: 7 May 2009 /Accepted: 8 October 2009 /Published online: 27 October 2009

(C) Springer-Verlag 2009

\begin{abstract}
In this study, we investigated the psychometric qualities of the Dutch version of the Maternal Antenatal Attachment Scale (MAAS). In a monocentric prospective observational cohort study, 403 expectant mothers completed a booklet with questionnaires in the first (T1), second (T2), and third (T3) pregnancy trimesters. In addition to the MAAS (T1-T3), the following measures were used: the MarloweCrowne Social Desirability Scale (T1), the Parental Bonding Inventory (T1), the Relationship Questionnaire (T1) the Facilitator scale and the Regulator scale (T3), the Edinburgh Postnatal Depression Scale (T1-T3) and the Pregnancy Related Anxiety Questionnaire (T1-T3). In this study, the mean of the MAAS scales increased as the pregnancy progressed. Good internal reliabilities were found for the Total MAAS scale, the Quality subscale and the Preoccupation subscale. Small-to-moderate correlations were found with social desirability, maternal orientation, parental care and adult attachment. Maternal mood was weakly associated with the quality but not with the intensity of the maternal
\end{abstract}

\footnotetext{
J. C. H. van Bussel $(\bowtie) \cdot K$. Demyttenaere

Institute of Family and Sexuality Sciences,

Department of Public Health, Faculty of Medicine,

Katholieke Universiteit Leuven,

Kapucijnenvoer 33,

3000 Leuven, Belgium

e-mail: johan.vanbussel@med.kuleuven.be

B. Spitz

Department of Gynaecology and Obstetrics,

University Hospital Gasthuisberg,

Leuven, Belgium

K. Demyttenaere

Department of Neurosciences and Psychiatry,

University Hospital Gasthuisberg,

Leuven, Belgium
}

attachment feelings. Overall, our findings suggest that the Dutch version of the Maternal Antenatal Attachment Scale is a reliable and valid measure of the early emotional tie between a pregnant woman and her unborn child.

Keywords Maternal antenatal attachment scale · Reliability · Validity · Pregnancy · Parental bonding · Adult attachment . Maternal orientation

\section{Introduction}

Since the pioneer work of Klaus and Kennell (1976) many researchers from various disciplines have focussed on the early development of the mother-infant relationship. Despite significant differences in, for example, terminology ("attachment" vs. "bonding") and the operationalisation of the phenomenon (observation of behaviour vs. self-reports of feelings), consensus exists about the fact that the development of the emotional bond between the mother and her child begins in early pregnancy (Shieh et al. 2001). Although few in number, most longitudinal studies on maternal antenatal attachment reported a gradual increase of attachment feelings towards the end of the pregnancy. Some studies, however, also identified women with stable or decreasing levels of maternal attachment feelings (Condon 1985; Grace 1989; Hjelmstedt et al. 2006; Mikulincer and Florian 1999). In the first trimester of their pregnancies, women are limited in the ways (tactile, visual ...) they can connect with the fetus inside (Rubin 1984). Some authors have suggested that women fill this gap with parental attachment representations from their own childhoods (Ilıcalı and Fișek 2004). Later, as the pregnancy progresses, a shift takes place from representations based on the past towards representations based on actual experiences, such 
as the quickening of the fetus (Damato 2004; Heidrich and Cranley 1989; Lerum and LoBiondo-Wood 1989; Rubin 1984 ) and its visualisation through an ultrasound scan (Ji et al. 2005; Lerum and LoBiondo-Wood 1989; Lumley 1990; Rustico et al. 2005). However, while evidence was found for the effect of the latter, the influence of childhood recollections of maternal care on maternal antenatal attachment is still speculative (Benoit and Parker 1994; Condon and Corkindale 1997; Pajulo et al. 2006; Priel and Besser 2000; Schwerdtfeger and Goff 2007; Siddiqui et al. 2000). On the other hand, strong associations have been found between the adult attachment representations of pregnant women and those of their own mothers (van IJzendoorn 1995).

Many studies have investigated the contributing and inhibiting factors of maternal antenatal attachment. As a result, a range of demographic (age, education, socioeconomic status), pregnancy-related clinical (risk status of current pregnancy, outcome of previous pregnancy), psychosocial (self-esteem, social support, coping style) and psychopathological (depressive and anxiety symptoms) variables have been identified as significant correlates of maternal antenatal attachment (Cannella 2005; Van den Bergh and Simons 2008).

In research, the emotional tie between a pregnant woman and the fetus is often measured with a self-report questionnaire (Van den Bergh and Simons 2009). One such instrument is the Maternal Antenatal Attachment Scale (MAAS) (Condon 1993). The theoretical basis of this questionnaire is a hierarchical model of adult attachment, designed by Condon (1993). Within this model, the love of the mother for the fetus is considered as the core experience of maternal attachment. This core experience, according Condon (1993), underpins five maternal dispositions towards the fetus (to know; to be with; to avoid separation or loss; to protect; and to gratify needs) which in turn mediate between the core attachment experience and overt maternal behaviours like information seeking, proximity seeking, protecting and pleasing. Items for the MAAS were pooled from unstructured interviews (based on the five postulated maternal dispositions) and tested in a pilot study (Condon 1985). The final study (Condon 1993) retained 19 items with a strong internal consistency (Cronbach's alpha of 0.82 ) and a fairly good spread of the responses. A subsequent factor analysis suggested a two factor structure for the MAAS. The first factor represented the quality (closeness vs. distance, tenderness vs. irritation etc.) of the emotional bond with the fetus whereas the second factor referred to the intensity of the preoccupation (amount of time spend thinking about, talking to, and palpating of the fetus) with the fetus (Condon 1993).

Condon (1993) also developed a model of four maternal antenatal attachment styles (Positively preoccupied, Posi- tively disinterested, Negatively preoccupied and Negatively disinterested) using the means of the Quality and Preoccupation subscales of the MAAS. According to Pollock and Percy (1999), the descriptions of Condon's maternal antenatal attachment styles seem to overlap with RaphaelLeff's (2005) model of maternal antenatal orientations. The positive preoccupied attachment style, for example, somewhat resembles to Raphael-Leff's Facilitator orientation. Indeed, in Raphael-Leff's (2005) work, Facilitators are considered to spend a lot of time interacting with their unborn children, in a preverbal (thinking), verbal and a physical (palpating) manner. The fetus is thereby perceived as a sociable communicative human being. Furthermore, this mother-child interaction is not only accompanied by feelings of closeness and selfless nurturance but is also characterized as a spontaneous adaptation (regression) towards the world of the child. In this sense, Raphael-Leff (2005) referred to Winnicott's (1956) notion of "primary maternal preoccupation." The negative preoccupied and negative disinterested attachment styles have, according to Pollock and Percy (1999), much in common with the Regulator orientation. Indeed, the fetus ("it") is to the Regulator more of a persecutory, invasive, and "parasitic intruder" (Raphael-Leff 2005). Furthermore, its movements are "experienced as alien and disconcerting, accompanied by anxiety, resentment, hostility, and denigration" (Pollock and Percy 1999). Raphael-Leff referred to this state as a state of "maternal primary persecution", the opposite of Winnicott's state of maternal primary preoccupation. Moreover, Regulators are thought to demonstrate only a minimal humanisation of the fetus and to pay little attention to antenatal preparation and health issues (Pollock and Percy 1999). Despite the similarities, no evidence on the convergence between the two models is available.

Although many studies included the MAAS in their research design, only a few of them focussed on its psychometric properties (Van den Bergh and Simons 2009). In this study, we therefore aimed to replicate previously published data on the psychometric properties of the MAAS using a Dutch version. In addition, we also explored the correlates and predictors of the responses on the MAAS. Finally, we classified the participants according to Condon's four class typology of antenatal attachment and reported the prevalence and stability of each class.

\section{Methods}

The present study is part of a monocentric longitudinal research project on maternal antenatal and postpartum mental health (July 2005-November 2007). Ethical approval for this study was received from the Medical Ethics Committee of the University Hospital Gasthuisberg, Leuven (5/7/2005). Re- 
cruitment of the participants, their background data, and the data collection used in this study were described in detail elsewhere (van Bussel et al. 2009a, b, c) and are briefly summarized here.

\section{Participants}

At a routine antenatal clinical at the University Hospital Gasthuisberg, Leuven (Belgium), pregnant women between 8 and 15 gestational weeks were invited to participate in this study. A nurse or midwife informed the women about the aims and design of the study. Women younger than 18 years old, those with a poor understanding of Dutch, and those with a major physical or psychological complication of the pregnancy were excluded from recruiting. Four hundred and three women, about $20 \%$ of the women who delivered in the hospital during that period, agreed to participate and gave their written consent.

The mean age of the participants was 30.15 years (SD 4.39), ranging from 19 to 44 years. Most participants in this study were Belgian women ( $n=390,96.77 \%)$, were married or lived as a couple $(n=382,95.50 \%)$, had completed tertiary education $(n=282,70.33 \%)$, and were employed $(n=370,92.04 \%)$. One hundred forty nine participants (38.95\%) were primigravida, $101(25.06 \%)$ had had a previous miscarriage, and 42 (10.45\%) had conceived after fertility treatment.

\section{Procedure}

The participants completed a booklet of questionnaires at three points in time: between 8 and 15 (T1), between 20 and 26 (T2), and between 30 and 36 (T3) gestational weeks. The first booklet was given at the hospital; the following booklets were posted to the participants' home addresses. Of the 403 women who participated in the first trimester, we received 330 booklets $(81.89 \%)$ at T2 and 298 booklets $(73.95 \%)$ at $\mathrm{T} 3$. The most frequent reasons for dropping out were miscarriage, occurrence of a pregnancy complication, and changed address.

\section{Measures}

\section{The maternal antenatal attachment scale (MAAS)}

The MAAS (Condon 1993) consists of 19 items divided over two subscales: "quality of attachment" (11 items) and "time spent in attachment mode" (8 items). The first subscale (further called "Quality") represents the quality of the mother's affective experiences towards the fetus (feelings of closeness and tenderness versus feelings of distance and irritation). The second subscale (further called "Preoccupation") represents the intensity of preoccupation with the fetus in regard to time spent thinking about, talking to, and palpating the fetus. All items are scored on a fivepoint scale. The minimum score for the Total MAAS is 19 and the maximum 95. The scores for the subscales theoretically range between 11 and 50 (Quality) and between 8 and 40 (Preoccupation). High scores reflect, respectively, a positive quality of attachment and a high intensity of preoccupation with the fetus. For this study, the MAAS was translated into Dutch and back translated into English both by the first author and an independent female scientific translator. Participants completed the MAAS in the first, second and third pregnancy trimester.

Four maternal antenatal attachment styles were differentiated using the means of the Quality subscale and the Preoccupation subscale of the current sample (Condon 1993). Participants with a total score higher than the mean for the Quality subscale and lower than or equal to the mean for the Preoccupation subscale were labelled as "Positively disinterested". Participants with a total score higher than the mean for the Preoccupation subscale and lower than or equal to the mean for the Quality subscale were labelled as "Negatively preoccupied". Participants scoring lower than or equal to the mean for both the Quality subscale and the Preoccupation subscale were labelled as "Negatively disinterested". Participants with a total score higher than the mean for both the Quality subscale and the Preoccupation subscale were labelled as "Positively preoccupied".

\section{Additional instruments}

The Dutch version (Hermans 1967) of the short MarloweCrowne Social Desirability Scale (MCSDS-10: Crowne and Marlowe 1960; Strahan and Gerbasi 1972) was used to determine participants' tendency to respond in a socially desirable manner. Possible answers to the items on this scale are true and not true. A high score on the MCSDS-10 reflects the tendency to respond in a socially desirable manner. As suggested by Strahan and Gerbasi (1972), we preferred the short version of the MCSDS to prevent practical problems that come with longer surveys (such as burdening the respondent). As expected, using this short version resulted in a lower internal reliability (0.41). Participants completed the MCSDS-10 in the second pregnancy trimester.

Retrospective data about the parent-child relation in participants' childhood was obtained with the Dutch version (Verschueren and Marcoen 1993) of the Parental Bonding Inventory (PBI: Parker et al. 1979). The PBI has two versions, a maternal and paternal version, with each having two subscales: "caring" (12 items) and "overprotection" (13 items). Responses are rated on a four-point scale: high scores reflect, respectively, a more affectionate, warm, and caring 
parent-child interaction and a more dominant and overprotective parent. The PBI is a widely used measure and has a satisfactory construct and convergent validity (Parker 1989). Previously, we reported Cronbach's reliability coefficients varying from 0.83 to 0.92 (van Bussel et al. 2009a). Participants completed the PBI in the first pregnancy trimester.

The participants' attachment style in close adult peer relationships were determined with the Dutch version (Lowyck et al. 2003) of the Relationship Questionnaire (RQ: Bartholomew and Horowitz 1991). This measure consists of four short paragraphs, each describing a prototypical attachment pattern (secure, fearful, preoccupied, and dismissing). Participants were asked to rate their degree of correspondence to each attachment pattern on a seven-point scale. The RQ shows convergent validity with interview ratings of adult attachment (Bartholomew and Horowitz 1991; Griffin and Bartholomew 1994). The RQ was completed by the participants in the first pregnancy trimester.

To determine women's maternal orientation as defined by Raphael-Leff (2005), the revised Facilitator scale and Regulator scale of the Placental Paradigm Questionnaire (PPQ: van Bussel et al. 2009c) were used. The PPQ is a questionnaire addressing specific antenatal emotional defences (idealization, persecution, obsession, and detachment) towards the self, the child, and the pregnancy (2005). Both scales consist of five items, such as "I feel more of a woman now that I'm pregnant" (Facilitator) and "I feel uneasy about sharing my body with the baby" (Regulator). Responses were rated on a four-point scale. A high score on either the Facilitator scale or the Regulator scale reflected the respondent's tendency to that maternal orientation. Previously, good-to-moderate internal reliabilities were reported for, respectively, the Facilitator scale $(\alpha: 0.75)$ and the Regulator scale ( $\alpha$ : 0.59) (van Bussel et al. 2009c). The women completed the Facilitator scale and the Regulator scale in the third trimester of their pregnancies.

The Dutch version (Pop et al. 1992) of the Edinburgh Postnatal Depression Scale (EPDS: Cox et al. 1987) was used to detect depressive symptoms in the participants:. The EPDS (10 items) has no physical indicators of psychological distress (headache, weight loss...) which could lead to false positive results due to the pregnancy. Responses on the EPDS are rated with a four-point (0 to 3 ) response category. The EPDS is a widely used measure with good reliability and validity in both a pregnant and postpartum population (Cox et al. 1987; Murray and Cox 1990). Previously, we reported Cronbach's alphas ranging between 0.80 and 0.84 (van Bussel et al. 2009b). For this study, we used the EPDS scores of the participants at T1, T2 and T3.

The Dutch Pregnancy Related Anxiety Questionnaire (PRAQ: Van den Bergh 1989) was used to measure specific fears and worries related to the participant's pregnancy. The PRAQ consists of 55 items divided over five subscales: fear for delivery ( 9 items), fear for the integrity of the baby (6 items), concerns about the changing partner relationship (11 items), concerns about the own mood and its effect on the baby (11 items), egocentric feelings/fear for changes ( 8 items). Responses are rated on a seven-point Likert scale ranging from "Does absolutely not apply" (1) to "Applies very well" (7). Previously, we reported high internal reliabilities for the total scale ( 0.95 on T1, T2 and T3) (van Bussel et al. 2009a). For this study, we used the total PRAQ scores of the participants at $\mathrm{T} 1, \mathrm{~T} 2$ and $\mathrm{T} 3$.

\section{Data analysis}

The SAS 9.1 software package was used for statistical analysis (SAS Institute Inc 2002). Descriptive statistics are presented in means and standard deviations, medians, ranges, absolute numbers and percentages. There was no imputation of missing data. If there were more than two missing values on a (sub)scale, no total for that scale was computed. Attrition analyses comparing differences in means of the MAAS scales at T1 for those who participated at all three time points of the study and those who dropped out, were performed with a Student's $t$ test. Linear mixedmodel analyses (Proc Mixed) were performed to observe differences in means (Least Squares Means) of repeated MAAS measurements. Relations between the MAAS scales, on the one hand, and the scales of the MCSDS-10, PPQ, PBI, RQ, EPDS and PRAQ were investigated using Pearson correlations when the responses on the variables were fairly normally distributed; otherwise, Spearman correlations $(\rho)$ were calculated. Bonferroni post-hoc tests were used to reduce the risk of Type-I errors.

\section{Results}

Descriptive statistics

The means, standard deviations, medians, minimum and maximum values of the total scale of the MAAS (further "Total MAAS") and the MAAS subscales are displayed in Table 1. Examination of the histograms of the Total MAAS and its Preoccupation subscale, revealed Gaussian but slightly leptokurtic distributions at all points of measurement. The Quality subscale was slightly negatively skewed. The distribution of Condon's (1993) maternal antenatal attachment styles is displayed in Table 2. Most participants were labelled as "Positively preoccupied" whereas the group of the "Negatively preoccupied" attachment style counted the least number of participants. 
Table 1 Means $(M)$, standard deviations $(S D)$, medians $(M d)$, minimum values $($ Min $)$ and maximum values $($ Max) of the Total MAAS and the MAAS subscales Quality and Preoccupation

\begin{tabular}{|c|c|c|c|c|c|c|c|c|c|c|c|c|c|c|c|}
\hline & \multicolumn{5}{|l|}{$\mathrm{T} 1$} & \multicolumn{5}{|l|}{$\mathrm{T} 2$} & \multicolumn{5}{|l|}{$\mathrm{T} 3$} \\
\hline & $M$ & $S D$ & $M d$ & Min & $\operatorname{Max}$ & $M$ & $S D$ & $M d$ & Min & $\operatorname{Max}$ & $M$ & $S D$ & $M d$ & Min & $\operatorname{Max}$ \\
\hline MAAS Total & 72.1 & 7.06 & 73 & 41 & 90 & 75.35 & 6.38 & 75 & 50 & 91 & 76.75 & 6.00 & 77 & 61 & 91 \\
\hline Quality & 43.79 & 3.73 & 44 & 28 & 50 & 45.51 & 3.17 & 46 & 34 & 50 & 46.03 & 2.76 & 46 & 37 & 50 \\
\hline Preoccupation & 26.49 & 4.53 & 27 & 12 & 40 & 28.04 & 4.34 & 28 & 15 & 40 & 29.04 & 4.27 & 29 & 17 & 40 \\
\hline
\end{tabular}

\section{Attrition effect}

We tested whether the MAAS mean scores at T1 for women who participated at all time points and those who dropped out differed significantly. No significant difference was found for the Total MAAS $(t=-1.70, p=0.09)$, the Quality subscale $(t=-1.65, p=0.10)$ nor the Preoccupation subscale $(t=-1.43, p=0.15)$.

The course of the MAAS

A linear mixed-model analysis $(F=156.74, d f=2, p<0.0001)$ revealed a significant increase of the Total MAAS scores in the second $(t=-11.62, d f=594$, adj. $p<0.0001)$ and third $(t=-6.44, d f=594$, adj. $p<0.0001)$ pregnancy trimesters, compared to, respectively, the first and second pregnancy trimesters. A similar repeated measures analysis for the Quality subscale of the MAAS ( $F=94.29, d f=2, p<0.0001$ ) revealed a significant increase of the mean in the second $(t=-10.12, d f=594$, adj. $p<0.0001)$ and third $(t=-3.72, d f=$ 594 , adj. $p=0.0002)$ pregnancy trimesters, compared to, respectively, the first and second pregnancy trimesters. Likewise, the mean of the Preoccupation subscale of the MAAS $(F=105.20, d f=2, p<0.0001)$ increased significantly in the second $(t=-8.22, d f=594$, adj. $p<0.0001)$ and third $(t=-6.60, d f=594$, adj. $p<0.0001)$ pregnancy trimesters, compared to, respectively, the first and second pregnancy trimesters. Of the four attachment styles, the "Positively preoccupied" style was the most stable attachment style while the "Negatively preoccupied" style was the least stable attachment style.

\section{Reliability}

Cronbach's alphas for the total MAAS scale were 0.79 (T1), 0.80 (T2) and 0.78 (T3). For the Quality subscale of the MAAS, following Cronbach's alphas were found: 0.73 (T1), 0.73 (T2) and 0.69 (T3). The Cronbach's alphas for the Preoccupation subscale were 0.76 (T1), 0.77 (T2) and 0.73 (T3).

Significant and moderately strong positive correlations were found between the Quality subscale and the Preoccupation subscale at T1 $(r=0.57, p<0.0001)$, T2 $(r=0.54, p<0.0001)$ and T3 $(r=0.55, p<0.0001)$. Further, the Total MAAS at T1 correlated strongly with the Total MAAS at T2 $(r=0.73, p<0.0001)$ and T3 $(r=0.72$, $p<0.0001)$. The Total MAAS at T2 correlated strongly with the Total MAAS at T3 $(r=0.79, p<0.0001)$. Similarly, the Quality subscale at $\mathrm{T} 1$ correlated moderately strongly with the Quality subscale T2 $(r=0.65, p<0.0001)$ and T3 $(r=0.58, p<0.0001)$. In addition, the Quality subscale at T2 correlated strongly with the Quality subscale at T3 $(r=0.69, p<0.0001)$. Finally, the Preoccupation subscale at T1 correlated strongly with the Preoccupation subscale at T2 $(r=0.72, p<0.0001)$ and T3 $(r=0.70, p<0.0001)$.

Table 2 Distribution of the maternal antenatal attachment styles according to Condon (1993)

\begin{tabular}{|c|c|c|c|c|c|c|c|c|}
\hline & \multicolumn{2}{|c|}{$\mathrm{T} 1(n=350)$} & \multicolumn{2}{|c|}{$\mathrm{T} 2(n=317)$} & \multicolumn{2}{|c|}{$\mathrm{T} 3(n=295)$} & \multicolumn{2}{|c|}{ All $\mathrm{T}^{\mathrm{b}}$} \\
\hline & $n$ & $\%$ & $n$ & $\%$ & $n$ & $\%$ & $n$ & $\%$ \\
\hline Positively preoccupied & 169 & 48.29 & 137 & 43.22 & 131 & 44.41 & 78 & 59.54 \\
\hline Positively disinterested & 67 & 19.14 & 76 & 23.97 & 59 & 20.00 & 12 & 20.34 \\
\hline Negatively preoccupied & 36 & 10.29 & 36 & 11.36 & 31 & 10.51 & 3 & 9.67 \\
\hline Negatively disinterested & 78 & 22.29 & 68 & 21.45 & 74 & 25.08 & 27 & 36.49 \\
\hline
\end{tabular}

We labelled less participants (T1: $n=53$, T2: $n=13$, and T3: $n=3$ ) than the total number of participants assessed at each point due to missing values on either the Quality or Preoccupation scale; ${ }^{\mathrm{b}}$ All T: participants holding the respective maternal antenatal attachment style at all points of measurement 
The Preoccupation subscale at T2 correlated strongly with the Preoccupation subscale at T3 $(r=0.80, p<0.0001)$.

Consistent and significant but small positive correlations were found between the MCSDS-10 (social desirability) and the Total MAAS, the Quality subscale and the Preoccupation subscale (Table 4).

\section{Convergent validity}

Significant moderate positive correlations were found between all MAAS scales and the Facilitator scale at T1, T2, and T3 (Table 4). Conversely, significant small-tomoderate negative correlations were found with the Regulator scale at T1, T2, and T3 (Table 4).

Determinants of maternal antenatal attachment

\section{Sociodemographic determinants}

Small-to-moderate negative correlations were found between maternal age on the one hand, and the Total MAAS $\left(r_{T 1}=\right.$ $-0.29, r_{T 2}=-0.29, r_{T 3}=-0.29$, all $\left.p<0.0001\right)$, the Quality subscale $\left(r_{T 1}=-0.22, r_{T 2}=-0.18, r_{T 3}=-0.23\right.$, all $\left.p<0.001\right)$ and the Preoccupation subscale $\left(r_{T 1}=-0.28, r_{T 2}=-0.30\right.$, $r_{T 3}=-0.26$, all $\left.p<0.0001\right)$ on the other. Primiparious women or women without a tertiary degree had higher scores on both the Total MAAS scale and the Preoccupation subscale compared to, respectively, multiparious women and women who completed tertiary education (Table 3). As for the Quality subscale, no differences in Least Squares Means (Proc Mixed with repeated measures) were found for any of the sociodemographic variables.

\section{Adult romantic attachment and memories of parental attachment during own childhood}

The maternal and paternal care scales (positively) and the secure (positively) and dismissing (negatively) attachment scales were consistently but weakly correlated with the Total MAAS and the Quality subscale (Table 4). The dismissing adult attachment scale was also negatively associated with the Preoccupation subscale of the MAAS. No or small and isolated significant correlations were found with the maternal and the paternal overprotection scales.

Associations with maternal mental health

Significant but small negative correlations were found between the Quality subscale of the MAAS on the one hand, and the EPDS and the PRAQ on the other (Table 4). No significant correlations were found with the Total Maas scale and the Preoccupation subscale.

\section{Discussion}

Reliability and construct validity of the MAAS

In this study, we investigated the psychometric qualities of the Dutch version of the Maternal Antenatal Attachment Scale (Condon 1993). Overall, both the Total MAAS and its subscales (Quality and Preoccupation) were found to be reliable and valid. As for the internal consistency of the scales, we found slightly lower Cronbach's alpha's as reported in the studies of Condon $(1993,1997)$. Nevertheless, the internal consistency found in our study was still good (Cronbach's alpha $\geq 0.70$ ) according to the criteria of Nunnally and Bernstein (1994). In addition, the strength of the correlations between the subscales found in this study was similar as that reported by Condon and Corkindale (1997) and significantly stronger than those reported by Priel and Besser (2000, 2001). There was also a good spread of the responses on the Total MAAS and its subscales. Furthermore, the means of the MAAS scales found in our study lie within the variance of those originally reported by Condon (1993) and those found in other studies of healthy singleton (Condon and Corkindale 1997; Hart and McMahon 2006; Priel and Besser 2000, 2001; Tsartsara and Johnson 2006) or twin pregnancies (Colpin et al. 1998).

It is reasonable to expect that self-reports of maternal emotions, cognitions and behaviours are susceptible to approval dependency and defensiveness (Bornstein and Cote 2004; Hjelmstedt et al. 2006; Sjögren et al. 2004). As part of our reliability analysis, we therefore investigated whether the responses on the MAAS were associated with the tendency to respond in a socially desirable manner. In our study too, more attached mothers were slightly more reluctant to admit unpopular beliefs or behaviours.

We used the mean scores of the MAAS subscales as cutoff scores to differentiate among maternal antenatal attachment styles. To our knowledge, only Pollock and Percy (1999) reported the distribution of the maternal antenatal attachment styles. However, our findings are difficult to compare given the specificity of Pollock and Percy's study population (the participants were referred to a Forensic Clinical Psychology department). In our study, most women were identified as having a healthy emotional tie with their unborn child (positively preoccupied). However, it should be noted that the classification was not stable over the three points of measurement. More importantly, however, is the question whether the differentiation into four styles truly represents a discrete structure of individual differences underlying the observed variation on the Quality subscale and the Preoccupation subscale. Furthermore, participants within a particular attachment style still vary considerably in the quality and quantity of 
Table 3 Least Squares Means (LSM) and Standard Errors (SE) of the Total MAAS and the subscales Quality and Preoccupation by sociodemographic variables (Proc Mixed with repeated measures)

\begin{tabular}{|c|c|c|c|c|c|c|c|c|c|}
\hline & \multicolumn{9}{|c|}{ MAAS } \\
\hline & \multicolumn{3}{|l|}{ Total } & \multicolumn{3}{|c|}{ Quality } & \multicolumn{3}{|c|}{ Preoccupation } \\
\hline & $L S M$ & SE & $t$ (DF 256) & $L S M$ & SE & $t$ (DF 256) & $L S M$ & SE & $t$ (DF 256) \\
\hline \multicolumn{10}{|l|}{ Tertiary education } \\
\hline Yes & 73.20 & 1.32 & $2.53 * *$ & 44.89 & 0.62 & 1.53 & 26.67 & 0.89 & $2.96 * * *$ \\
\hline No & 75.24 & 1.36 & & 45.46 & 0.64 & & 28.28 & 0.91 & \\
\hline \multicolumn{10}{|l|}{ Employment } \\
\hline Yes & 75.73 & 1.15 & -1.87 & 45.92 & 0.54 & -1.93 & 28.38 & 0.77 & -1.70 \\
\hline No & 72.72 & 1.80 & & 44.42 & 0.86 & & 26.56 & 1.20 & \\
\hline \multicolumn{10}{|c|}{ Living with partner } \\
\hline Yes & 74.32 & 0.92 & -0.10 & 44.78 & 0.44 & 0.81 & 27.73 & 0.61 & -0.36 \\
\hline No & 74.12 & 2.14 & & 45.57 & 1.00 & & 27.22 & 1.44 & \\
\hline \multicolumn{10}{|l|}{ Gravidity } \\
\hline Primigravidity & 74.04 & 1.60 & 0.26 & 45.15 & 0.75 & 0.08 & 27.52 & 1.07 & -0.10 \\
\hline Multigravidity & 74.41 & 1.33 & & 45.20 & 0.62 & & 27.42 & 0.89 & \\
\hline \multicolumn{10}{|l|}{ Parity } \\
\hline Primiparity & 75.74 & 1.30 & $-2.49 * *$ & 45.40 & 0.61 & -0.81 & 28.64 & 0.87 & $-2.84 * * *$ \\
\hline Multiparity & 72.71 & 1.52 & & 44.95 & 0.71 & & 26.30 & 1.02 & \\
\hline \multicolumn{10}{|c|}{ Previous miscarriage } \\
\hline Yes & 73.94 & 1.44 & 0.54 & 44.90 & 0.68 & 1.15 & 27.54 & 0.97 & -0.19 \\
\hline No & 74.50 & 1.31 & & 45.45 & 0.62 & & 27.41 & 0.88 & \\
\hline \multicolumn{10}{|c|}{ Assisted conception } \\
\hline Yes & 74.79 & 1.47 & -1.10 & 45.54 & 0.69 & -1.54 & 27.65 & 0.99 & -0.50 \\
\hline No & 73.66 & 1.27 & & 44.80 & 0.60 & & 27.30 & 0.85 & \\
\hline
\end{tabular}

* adj. $p<0.05 ; * *$ adj. $p<0.01 ; * * *$ adj. $p<0.001$

their maternal attachment feelings (Crowell et al. 1999). Therefore, results based on Condon's (1993) categorical model need a cautious interpretation.

Most studies using the MAAS were unable to report the course of maternal antenatal attachment scores over all three pregnancy trimesters. In our study, we found that the degree of attachment increases both in quality and quantity as the pregnancy progresses. It however seems that the increase in the third trimester is not that large compared to that in the second trimester. A possible explanation lies in the unconscious defence mechanisms described by Stern (1995). According to Stern (1995), maternal attachment representations of the fetus increase in richness, intensity, and specificity from the fourth until the seventh month of pregnancy. During the last two months of the pregnancy, however, mothers seem to "undo" their more positive representations in order to prevent a "potential discordance between the real baby and a too specifically represented baby" (Stern 1995).

As part of the construct validity of the MAAS, we investigated its convergence with the scales based on
Raphael-Leff's (2005) model of maternal antenatal orientations. As suggested by Pollock and Percy (1999), women in our study tending to the Facilitator orientation were indeed more preoccupied with their children and reported more positive feelings of attachment, whereas women tending to the Regulator orientation reported less preoccupation and less positive attachment feelings.

Determinants of maternal antenatal attachment

According to Rubin (1984), women realign and tighten the bonds with their mothers when they become pregnant and search for a new (maternal) identity or self. Klaus and Kennell (1976) also postulated that women's caretaking and attachment behaviour is determined by the mothering in their own childhoods. In our study, women recalling a more affectionate, warm, and caring parent had only slightly more positive and intense attachment feelings towards their fetuses. Most previous studies found no significant association between pregnant women's memories of maternal attachment during their own childhood 
Table 4 Correlations between maternal attachment during pregnancy (MAAS) and the independent study variables

MAAS

\begin{tabular}{|c|c|c|c|c|c|c|c|c|}
\hline \multicolumn{3}{|c|}{ Total } & \multicolumn{3}{|c|}{ Quality } & \multicolumn{3}{|c|}{ Preoccupation } \\
\hline $\mathrm{T} 1$ & $\mathrm{~T} 2$ & $\mathrm{~T} 3$ & $\mathrm{~T} 1$ & $\mathrm{~T} 2$ & $\mathrm{~T} 3$ & $\mathrm{~T} 1$ & $\mathrm{~T} 2$ & $\mathrm{~T} 3$ \\
\hline
\end{tabular}

\begin{tabular}{|c|c|c|c|c|c|c|c|c|c|}
\hline \multicolumn{10}{|l|}{ Social Desirability } \\
\hline MCSDS-10 & $0.15^{* * *}$ & $0.15^{* * *}$ & $0.19^{* * *}$ & $0.14^{* *}$ & $0.15^{* * *}$ & $0.17^{* * *}$ & $0.11^{*}$ & $0.13^{* *}$ & $0.17^{* * *}$ \\
\hline \multicolumn{10}{|c|}{ Maternal antenatal orientation } \\
\hline Facilitator orientation & $0.38^{\#}$ & $0.37^{\#}$ & $0.48^{\#}$ & $0.29^{\#}$ & $0.32^{\#}$ & $0.40^{\#}$ & $0.36^{\#}$ & $0.35^{\#}$ & $0.40^{\#}$ \\
\hline Regulator orientation & $-0.27^{\#}$ & $-0.23^{\#}$ & $-0.27^{\#}$ & $-0.28^{\#}$ & $-0.29^{\#}$ & $-0.37^{\#}$ & $-0.18^{* * *}$ & $-0.13^{* *}$ & $-0.12^{* *}$ \\
\hline \multicolumn{10}{|l|}{ Parental bonding } \\
\hline Maternal Care & $0.22^{\#}$ & $0.19^{\#}$ & $0.18^{\#}$ & $0.25^{\#}$ & $0.21^{\#}$ & $0.18^{* * *}$ & $0.15^{* * *}$ & $0.14^{* *}$ & $0.13^{* *}$ \\
\hline Maternal Overprotection & 0.03 & -0.05 & -0.06 & 0.02 & -0.02 & -0.04 & 0.05 & -0.05 & -0.02 \\
\hline Paternal Care & $0.20^{\#}$ & $0.15^{* *}$ & $0.17^{\#}$ & $0.17^{* * *}$ & 0.10 & $0.18^{* * *}$ & $0.15^{* *}$ & $0.14^{* *}$ & 0.11 \\
\hline Paternal Overprotection & $-0.12^{* *}$ & -0.08 & -0.09 & -0.09 & -0.06 & -0.09 & -0.09 & -0.06 & -0.05 \\
\hline \multicolumn{10}{|l|}{ Adult attachment } \\
\hline Secure adult attach. & $0.17^{\#}$ & $0.16^{\#}$ & $0.20^{\#}$ & $0.22^{\#}$ & $0.21^{\#}$ & $0.20^{\#}$ & 0.09 & 0.10 & $0.17^{* * *}$ \\
\hline Fearful adult attach. & $-0.13^{* *}$ & $-0.12^{* *}$ & $-0.12^{* *}$ & $-0.20^{\#}$ & $-0.24^{\#}$ & $-0.20^{\#}$ & -0.05 & -0.03 & -0.04 \\
\hline Preoccupied adult attach. & -0.09 & -0.08 & -0.10 & $-0.16^{* * *}$ & $-0.18^{* * *}$ & $-0.19^{* * *}$ & 0.01 & -0.01 & -0.02 \\
\hline Dismissing adult attach. & $-0.16^{\#}$ & $-0.14^{* *}$ & $-0.15^{* *}$ & $-0.18^{\#}$ & $-0.17^{* * *}$ & $-0.19^{* * *}$ & $-0.10^{* *}$ & $-0.12^{* *}$ & $-0.13^{* *}$ \\
\hline \multicolumn{10}{|l|}{ Depressive symptomatology } \\
\hline EPDS & -0.02 & 0.04 & 0.04 & $-0.11^{* *}$ & $-0.19^{\#}$ & $-0.18^{* * *}$ & 0.09 & 0.03 & 0.12 \\
\hline \multicolumn{10}{|l|}{ Pregnancy related anxiety } \\
\hline PRAQ & 0.09 & 0.02 & 0.03 & $-0.14^{* *}$ & $-0.20^{\#}$ & $-0.18^{* * *}$ & 0.08 & 0.04 & 0.11 \\
\hline
\end{tabular}

${ }^{\#} p=0.06 ;{ }^{*} p<0.05 ; * * p<0.01 ; * * * p<0.001$

and maternal attachment in their own pregnancies (Condon and Corkindale 1997; Priel and Besser 2000; Schwerdtfeger and Goff 2007). Alternatively, it has been suggested that the developmental task of building a selfidentity as a mother is guided by current patterns of attachment rather than by representations based on the past (Priel and Besser 1999; Ruble et al. 1990). However, and in contrast with the studies of Priel and Besser (2000, 2001), we did not find a strong relationship between the maternal attachment representations of the fetus and the current adult attachment style of the mother. Nevertheless, most of our findings fit with attachment theory and previous research. For example, securely attached mothers reported more positive maternal attachment feelings whereas insecure attached mothers reported less positive feelings of maternal attachment. In addition, women with a more dismissing adult attachment style were less preoccupied with their fetuses.

In line with previous studies (Damato 2004; Hjelmstedt et al. 2006; Siddiqui et al. 1999), we found that older women were both slightly less positive and less preoccupied with their fetuses. A possible explanation could be that older women are more concerned about the changes that come with a pregnancy and a new child (Damato 2004).
Younger women are also assumed to attribute more value to the pregnancy in terms of role fulfilment (Damato 2004). Both arguments also could explain why the higher educated women and the multigravida of our study were less preoccupied with their fetuses. It is, however, important to mention that both groups of pregnant women did not differ from their counterparts in the qualitative dimension of the affective relationship with their fetuses.

\section{Maternal antenatal attachment and mental health}

In our study, women with more depressive or anxiety symptoms reported less positive feelings of attachment towards their fetuses. Their mood state, however, seemed not to interfere with the intensity of their maternal attachment feelings. Similar results have been reported by Hart and McMahon (2006) and Condon and Corkindale (1997). A plausible explanation is that the intensity of women's preoccupation with their fetuses is more determined by external factors like employment or the presence of other children (Hart and McMahon 2006). Overall, our findings again underscore the added value of the differentiation of a total attachment score in its qualitative and quantitative dimension. As for the relation with pregnancy 
related anxiety, the low correlations are possibly due to the fact that the PRAQ covers a substantial number of items that are not related to the fetus but to the delivery, the partner relationship or the changes that come with motherhood.

Based on our findings, it could be suggested that women tending to the Positive preoccupation attachment style, when compared with the other antenatal attachment styles, have healthier relationships with their fetuses. However, as Sjögren et al. (2004) have postulated, high attachment scores do not necessarily predict a healthier mother-child relationship. On the other hand, given the established research on maternal sensitivity (De Wolff and van Ijzendoorn 1997), the maternal dispositions underpinning the Positive preoccupation style "may be particularly adaptive to the needs of early infancy, so that a subsequent secure attachment with the mother will follow" (Scher 2001). Indeed, the heightened state of primary maternal preoccupation becomes problematic only if the mother goes on to identify herself with the child and if she does not regain her own self-interest (Raphael-Leff 2005; Winnicott 1968). The negative disinterested attachment style, on the other hand, given the largely negative representations of the unborn child (cfr. state of primary maternal persecution), is expected to be less sensitive towards her child. As a result, her child is likely to become insecurely attached to the mother (Scher 2001).

\section{Limitations}

Several limitations of this study need to be addressed. First, this study relied on the elective enrolment of the participants. A selection bias is possible given that the participants in this study were rather well educated and employed. On the other hand, our study population was somewhat representative of both the population of women visiting the antenatal clinic of the UZ Gasthuisberg and the women living in the region of the hospital. Second, much of the data are taken from responses to questionnaires. Although most of them are well validated, an eventual reporting bias is difficult to prevent or estimate. Furthermore, controversy exists about the ability of self-report measures to capture the unconscious processes underlying the respondents' attachment styles (Berant 2005). Third, a retrospective assessment was used to collect data on the parenting received by participants' during childhood. Generally, retrospective assessments are considered to be unreliable and invalid (Hardt and Rutter 2004). As for the PBI, high test-retest reliability was found in a non-clinical cohort over 10 and 20 years (Wilhelm et al. 2005; Wilhelm and Parker 1990). Also, depression and life-event experiences had only a small effect on the stability of the perception of parenting as measured by the PBI (Wilhelm et al. 2005). Nevertheless, one should take into account that the PBI may not measure those aspects of early interactions that are essential for the development of maternal antenatal attachment (Myhr et al. 2004). Fourth, we measured the maternal orientation during the third pregnancy trimester and used it to predict, retrospectively, the degree of maternal attachment in the first and second pregnancy trimesters. Therefore, interpretation of these results assumes that the maternal orientation is a fairly stable trait over the whole course of the pregnancy, as suggested by Raphael-Leff (2005).

\section{Conclusion}

The Dutch version of the Maternal Antenatal Attachment Scale is a reliable and valid measure of the early emotional tie between a pregnant woman and her unborn child. Because attachment specific clinical interviews are sometimes difficult to implement in an obstetric and primary care unit (lack of facilities or specific training), a questionnaire like the MAAS is a very useful tool to screen for a potentially disordered mother-infant relationship (Klier 2006). Furthermore, the results may facilitate both the establishment of a prevention plan and the evaluation of the improvement over time (Klier 2006).

\section{References}

Bartholomew K, Horowitz LM (1991) Attachment styles among young adults: a test of a four-category model. J Pers Soc Psychol 61(2):226-244

Benoit D, Parker KC (1994) Stability and transmission of attachment across three generations. Child Dev 65(5):1444-1456

Berant E (2005) Rorschach correlates of self-reported attachment dimensions: dynamic manifestations of hyperactivating and deactivating strategies. J Pers Assess 84(1):70

Bornstein MH, Cote LR (2004) Mothers' parenting cognitions in cultures of origin, acculturating cultures, and cultures of destination. Child Dev 75(1):221-235

Cannella BL (2005) Maternal-fetal attachment: an integrative review. J Adv Nurs 50(1):60-68

Colpin H, De Munter A, Nys K, Vandemeulebroecke L (1998) Prenatal attachment in future parents of twins. Early Dev Parent 7:223-227

Condon JT (1985) The parental-foetal relationship: a comparison of male and female expectant parents. J Psychosom Obstet Gynaecol 4:271-284

Condon JT (1993) The assessment of antenatal emotional attachment: development of a questionnaire instrument. Br J Med Psychol 66 (Pt 2):167-183

Condon JT, Corkindale C (1997) The correlates of antenatal attachment in pregnant women. Br J Med Psychol 70(Pt 4):359-372

Cox JL, Holden JM, Sagovsky R (1987) Detection of postnatal depression. Development of the 10-item edinburgh postnatal depression scale. Br J Psychiatry 150:782-786

Crowell JA, Fraley RC, Shaver PR (1999) Measurement of individual differences in adolescent and adult attachment. In: Cassidy J, 
Shaver PR (eds) Handbook of attachment. Theory, research, and clinical applications. Guilford, London, pp 434-465

Crowne DP, Marlowe D (1960) A new scale of social desirability independent of psychopathology. J Consult Psychol 24:349-354

Damato EG (2004) Predictors of prenatal attachment in mothers of twins. J Obstet Gynecol Neonatal Nurs 33(4):436-445

De Wolff MS, van Ijzendoorn MH (1997) Sensitivity and attachment: a meta-analysis on parental antecedents of infant attachment. Child Dev 68(4):571-591

Grace JT (1989) Development of maternal-fetal attachment during pregnancy. Nurs Res 38(4):228-232

Griffin DW, Bartholomew K (1994) The metaphysics of measurement: The case of adult attachment. In: Bartholomew K, Perlman D (eds) Advances in personal relationships (Vol. Vol. 5: Attachment Processes in Adulthood, pp. 17-52). Jessica Kingsley, London

Hardt J, Rutter M (2004) Validity of adult retrospective reports of adverse childhood experiences: review of the evidence. J Child Psychol Psychiatry 45(2):260-273

Hart R, McMahon CA (2006) Mood state and psychological adjustment to pregnancy. Arch Womens Ment Health 9(6):329 337

Heidrich SM, Cranley MS (1989) Effect of fetal movement, ultrasound scans, and amniocentesis on maternal-fetal attachment. Nurs Res 38(2):81-84

Hermans H (1967) Sociale wenselijkheids schaal, SW (Social Desirability Scale). Catholic University of Nijmegen, Nijmegen

Hjelmstedt A, Widstrom AM, Collins A (2006) Psychological correlates of prenatal attachment in women who conceived after in vitro fertilization and women who conceived naturally. Birth 33(4):303-310

Ilıcalı E, Fișek GO (2004) Maternal representations during pregnancy and early motherhood. Infant Mental Health Journal 25:16-27

Ji EK, Pretorius DH, Newton R, Uyan K, Hull AD, Hollenbach K et al (2005) Effects of ultrasound on maternal-fetal bonding: a comparison of two- and three-dimensional imaging. Ultrasound Obstet Gynecol 25(5):473-477

Klaus M, Kennell J (1976) Maternal-infant bonding. C.V. Mosby Company, St Louis

Klier CM (2006) Mother-infant bonding disorders in patients with postnatal depression: the postpartum bonding questionnaire in clinical practice. Arch Womens Ment Health 9(5):289-291

Lerum CW, LoBiondo-Wood G (1989) The relationship of maternal age, quickening, and physical symptoms of pregnancy to the development of maternal-fetal attachment. Birth 16(1):13-17

Lowyck B, Luyten P, Hutsebaut J, Corveleyn J (2003) De relatievragenlijst van Bartholomew \& Horowitz. Center for Psychoanalysis and Psychodynamic Psychology (K.U.Leuven), Leuven

Lumley J (1990) Through a glass darkly: ultrasound and prenatal bonding. Birth 17(4):214-217

Mikulincer M, Florian V (1999) Maternal-fetal bonding, coping strategies, and mental health during pregnancy: The contribution of attachment style. Infant Ment Health J 18(3):255-276

Murray D, Cox JL (1990) Screening for depression during pregnancy with the edinburgh depression scale (EDDS). J Reprod Infant Psychol 8(2):99-107

Myhr G, Sookman D, Pinard G (2004) Attachment security and parental bonding in adults with obsessive-compulsive disorder: a comparison with depressed out-patients and healthy controls. Acta Psychiatr Scand 109(6):447-456

Nunnally J, Bernstein I (1994) Psychometric theory. McGraw Hill, New York

Pajulo M, Helenius H, Mayes L (2006) Prenatal views of baby and parenthood: association with sociodemographic and pregnancy factors. Infant Ment Health J 27(3):229-250

Parker G (1989) The parental bonding instrument: psychometric properties reviewed. Psychiatr Dev 7(4):317-335
Parker G, Tupling H, Brown L (1979) A parental bonding instrument. J Med Psychol 52:1-10

Pollock PH, Percy A (1999) Maternal antenatal attachment style and potential fetal abuse. Child Abuse Negl 23(12):1345-1357

Pop VJ, Komproe IH, van Son MJ (1992) Characteristics of the edinburgh post natal depression scale in the netherlands. J Affect Disord 26(2):105-110

Priel B, Besser A (1999) Vulnerability to postpartum depressive symptomatology: dependency, self-criticism and the moderating role of antenatal attachment. J Soc Clin Psych 18:240-253

Priel B, Besser A (2000) Adult attachment styles, early relationships, antenatal attachment, and perceptions of infant temperament: a study of first-time mothers. Pers Relatsh 7(3):291-310

Priel B, Besser A (2001) Bridging the gap between attachment and object relations theories: a study of the transition to motherhood. Br J Med Psychol 74(Pt 1):85-100

Raphael-Leff J (2005) Psychological processes of childbearing. The Anna Freud Centre, London

Rubin R (1984) Maternal identity and the maternal experience. Springer, New York

Ruble DN, Brooks-Gunn J, Fleming AS, Fitzmaurice G, Stangor C, Deutsch F (1990) Transition to motherhood and the self: measurement, stability, and change. J Pers Soc Psychol 58 (3): $450-463$

Rustico MA, Mastromatteo C, Grigio M, Maggioni C, Gregori D, Nicolini U (2005) Two-dimensional vs. two- plus fourdimensional ultrasound in pregnancy and the effect on maternal emotional status: a randomized study. Ultrasound Obstet Gynecol 25(5):468-472

SAS Institute Inc. (2002). SAS Software Version 9.1 of the SAS System for Windows (Version 9.1). Cary NC: SAS Institute Inc.

Scher A (2001) Facilitators and regulators: maternal orientation as an antecedent of attachment security. J Reprod Infant Psychol 19 (4):325-333

Schwerdtfeger KL, Goff BS (2007) Intergenerational transmission of trauma: exploring mother-infant prenatal attachment. J Trauma Stress 20(1):39-51

Shieh C, Kravitz M, Wang HH (2001) What do we know about maternal-fetal attachment? Kaohsiung J Med Sci 17(9):448-454

Siddiqui A, Hägglöf B, Eisemann M (1999) An exploration of prenatal attachment in Swedish expectant women. J Reprod Infant Psychol 17(4):369-380

Siddiqui A, Hägglöf B, Eisemann M (2000) Own memories of upbringing as a determinant of prenatal attachment in expectant women. J Reprod Infant Psychol 18(1):67-74

Sjögren B, Edman G, Widström AM, Mathiesen AS, Uvnäs-Moberg K (2004) Maternal foetal attachment and personality during first pregnancy. J Reprod Infant Psychol 22(2):57-69

Stern DN (1995) The motherhood constellation a unified view of parent-infant psychotherapy. Basic Books, New York

Strahan R, Gerbasi K (1972) Short, homogeneous versions of the marlowe-crowne social desirability scale. J Clin Psychol 28:191-193

Tsartsara E, Johnson MP (2006) The impact of miscarriage on women's pregnancy-specific anxiety and feelings of prenatal maternal-fetal attachment during the course of a subsequent pregnancy: an exploratory follow-up study. J Psychosom Obstet Gynaecol 27(3):173-182

van Bussel JCH, Spitz B, Demyttenaere K (2009a) Anxiety in pregnant and postpartum women. An exploratory study of the role of maternal orientations. J Affect Disord 114(1-3):232-242

van Bussel JCH, Spitz B, Demyttenaere K (2009b) Depressive symptomatology in pregnant and postpartum women. An exploratory study of the role of maternal orientations. Arch Womens Ment Health 12 (3):155-166

van Bussel JCH, Spitz B, Demyttenaere K (2009c) Maternal antenatal orientations on pregnancy, the child and motherhood, reliability 
and construct validity of a brief measure. Individual Differences Research. In press

Van den Bergh BRH (1989) De emotionele toestand van de (zwangere) vrouw, obstretische complicaties en het gedrag en de ontwikkeling van de foetus en van het kind tot de leeftijd van zeven maanden [The emotional state of the (pregnant) woman, obstetrical complications and the behavior and development of fetus and child until seven months after birth], Unpublished doctoral dissertation. Katholieke Universiteit Leuven, Leuven.

Van den Bergh BRH, Simons A (2009) A review of scales to measure the mother-foetus relationship. J Reprod Infant Psychol 27 (2):114-126

van IJzendoorn MH (1995) Adult attachment representations, parental responsiveness, and infant attachment: a meta-analysis on the predictive validity of the adult attachment interview. Psychol Bull 117(3):387-403

Verschueren K, Marcoen A (1993) Gehechtheidsstijl, intimiteit en vertrouwen in de jongvolwassenheid: een reflectie van de ervaren ouderlijke sensitiviteit? Psychol Belg 33:49-76

Wilhelm K, Niven H, Parker G, Hadzi-Pavlovic D (2005) The stability of the parental bonding instrument over a 20-year period. Psychol Med 35(3):387-393

Wilhelm K, Parker G (1990) Reliability of the parental bonding instrument and intimate bond measure scales. Aust NZ J Psychiatry 24(2):199-202

Winnicott DW (1956) Primary maternal preoccupation. In Through Paediatrics to Psychoanalysis. London: Hogarth.

Winnicott DW (1968) The family and individual development. Routledge, London 